\title{
Work-related upper extremity disorders: one-year follow-up in an occupational diseases registry
}

\author{
D. Spreeuwers • A. G. E. M. de Boer · J. H. A. M. Verbeek • \\ M. M. van Beurden • N. S. de Wilde • I. Braam • \\ Y. Willemse • T. M. Pal • F. J. H. van Dijk
}

Received: 28 July 2010/ Accepted: 12 January 2011/Published online: 28 January 2011

(C) The Author(s) 2011. This article is published with open access at Springerlink.com

\begin{abstract}
Purpose To study the course and consequences of workrelated upper extremity disorders in the registry of the Netherlands Centre for Occupational Diseases (NCvB).

Methods A follow-up study was performed in a sample of consecutive cases of work-related upper extremity disorders notified to the NCvB. Perceived severity was measured with VAS (0-100), quality of life with VAS (0-100) and SF-36, functional impairment with DASH and sickness absence with a questionnaire. Measurements took place directly after notification (T0) and after 3, 6 and 12 months (T1-T3). A linear mixed model was used to compare scores over time.

Results Average age of the 48 consecutive patients (89\% response) was 42 years; $48 \%$ were men. Perceived severity, functional impairment and sickness absence decreased statistically significant during the follow-up period, and quality of life scores improved. Patients older than 45 years scored worse on perceived severity of the disease, functional impairment and quality of life than did younger patients.

Conclusions The role of registries of occupational diseases for preventive policy can be extended by creating longitudinal data in sample projects. In the sample from
\end{abstract}

D. Spreeuwers $(\varangle) \cdot$ A. G. E. M. de Boer

J. H. A. M. Verbeek · M. M. van Beurden .

N. S. de Wilde - I. Braam · Y. Willemse ·

T. M. Pal · F. J. H. van Dijk

Coronel Institute of Occupational Health,

Academic Medical Center, University of Amsterdam,

PO Box 22700, 1100 DE Amsterdam, The Netherlands

e-mail: d.spreeuwers@amc.uva.nl

J. H. A. M. Verbeek

Finnish Institute of Occupational Health, Kuopio, Finland our registry, work-related upper extremity disorders had a favourable course.

Keywords Occupational diseases - Registries .

Follow-up · Upper extremity disorders .

Functional impairment

\section{Introduction}

Work-related upper extremity disorders are among the most common disorders seen by general practitioners and occupational physicians. In several countries, e.g. the United Kingdom (Chen et al. 2005), Finland (Riihimäki et al. 2004) and France (CNAMTS 2007), work-related upper extremity disorders account for a large part of the total number of reported occupational diseases. In the Fourth European Working Conditions survey of the European Foundation for the Improvement of Living and Working Conditions carried out in 2005 in the $27 \mathrm{EU}$ Member States, 24\% of the working population reported work-related muscular pain (European Foundation for the Improvement of Living and Working Conditions 2007). Work-related upper extremity disorders-which represent $22 \%$ of all occupational diseases reported in 2006-are the category of diseases most frequently reported to the registry of the Netherlands Centre for Occupational Diseases (NCvB) (Spreeuwers et al. 2007).

The definition of the group of upper extremity disorders is rather wide. Van Eerd et al. (2003) found 27 different classification systems in the literature. The registry of the $\mathrm{NCvB}$ uses the classification of Sluiter et al. (2001) that is based on a comprehensive international collaboration project.

The impact of work-related upper extremity disorders on the individual and the societal level can be substantial. 
A survey in the Netherlands revealed that annually, $8 \%$ of the working population suffers from upper extremity musculoskeletal complaints including sickness absence. In $2.3 \%$ of the cases, the duration of sickness absence was more than 4 weeks (Blatter 2001). In the United Kingdom, an estimated 10.7 million working days (full-day equivalents) were lost in 2006/7 through musculoskeletal disorders caused or aggravated by work. On average, each person suffering from a work-related upper extremity disorder took off an estimated 16.7 days in that 12-month period, which equates to an annual loss of 0.46 days per worker (HSE 2007). Hashemi et al. (1998) found that disability duration of more than 3 months was typical in cases of indemnity claims.

For the patient, work-related upper extremity disorders can result in persisting symptoms and difficulties in performing simple activities of daily living, job loss, symptoms of depression and family disruption. Keogh et al. (2000) found that $53 \%$ of the group of patients with workrelated upper extremity disorders, who had claimed compensation, reported persistent symptoms that were severe enough to interfere with work during 4 years post-claim.

Morse et al. (1998) found that work-related upper extremity disorders can have a substantial social and economic impact on workers, such as divorce or loss of the home. Ekberg and Wildhagen (1996) found that long-term sickness absence is associated with worse ratings in quality of life after 1-year and that pain did not diminish during the follow-up year.

Information on the severity and impact of the diseases is important for decision-making in preventive policy. Moreover, the incidence rate, the severity and the impact of a disease can provide arguments when deciding for which diseases preventive activities should be financed. In general, registries of occupational diseases do not provide information on the severity or impact of the diseases (Karjalainen and Niederlaender 2004). Despite variations in registration guidelines in different countries, general occupational disease registries probably contain the relatively more severe cases of occupational disease, which result in relatively higher costs. Therefore, it might be relevant for policy purposes to perform follow-up studies of the cases from registries. In addition, periodically executed small-scale follow-up studies linked to registries will probably be less expensive and more efficient than a series of cohort studies.

The aim of this study was to investigate the perceived severity and the consequences of the upper extremity disorders that are registered as occupational diseases. Severity, functional impairment, quality of life and sickness absence were assessed over the course of 1 year and compared with reference data on the general working population.

\section{Methods}

Population

In the Netherlands, occupational physicians are obliged to notify cases of occupational diseases to the registry of the NCvB. Besides classic occupational diseases like occupational asthma or mesothelioma, this registry also covers work-related diseases like work-related depression or musculoskeletal diseases. The registry distinguishes eleven categories of work-related specific disorders of the upper extremity: radiating neck complaints; rotator cuff syndrome; epicondylitis (lateral and medial); ulnar nerve compression at the elbow (cubital tunnel syndrome); radial nerve compression (radial tunnel syndrome); flexor-extensor peritendinitis or tenosynovitis of the forearm-wrist region; de Quervain's disease; carpal tunnel syndrome; ulnar nerve compression at the wrist (Guyon canal syndrome); Raynaud's phenomenon and peripheral neuropathy associated with hand-arm vibration; and osteoarthrosis of distal upper extremity joints. In addition, a twelfth category of non-specific upper extremity musculoskeletal disorders has been described (Sluiter et al. 2001).

We asked occupational physicians, who had participated in an NCvB sentinel surveillance project, to recruit patients, who had been diagnosed with a work-related upper extremity disorder, to participate in this study and to ask them to fill out an informed consent form. After signing the form, the patients received a questionnaire. Patients had to complete this questionnaire directly after notification in order to be included in the study. Patients could withdraw from the study at any moment.

\section{Study design}

We performed a follow-up study in a sample of consecutive cases notified to the $\mathrm{NCvB}$ with work-related upper extremity disorders. The notifications originated from a sentinel surveillance project carried out by the $\mathrm{NCvB}$ between 1 October 2003 and 1 July 2005 (Spreeuwers et al. 2008). Baseline measurements were made directly after notification and follow-up measurements after 3, 6 and 12 months.

Before the study, we held an introductory meeting to instruct the participating occupational physicians. The informed consent forms handed out by the physicians were provided with a code corresponding to the notification of the case to the NCvB. This allowed us to link the questionnaires to the cases in our database of reported occupational diseases.

As soon as we received an informed consent form, we sent the patient a questionnaire (T0). If the patient did not return the completed questionnaire within 4 weeks, we sent 
a reminder. After 3, 6 and 12 months (T1, T2 and T3), we sent follow-up questionnaires; if necessary, we sent a reminder 4 weeks later.

\section{Measurements}

The questionnaires sent to the patients at $\mathrm{T} 0, \mathrm{~T} 1, \mathrm{~T} 2$ and $\mathrm{T} 3$ had the same content. The general part of the questionnaire included questions about the patients' personal situation (age, sex, marital status, number of children, level of education), occupation and number of working hours, co-morbidity, annual income (in euros), medical treatment (consultations, diagnostic examinations, hospital treatment, medication) and work interventions (adjustments in the workplace, personal aids, training, coaching, replacement). The relation between these determinants and the origin, course and consequences of occupational diseases are presented in Fig. 1.

We used a visual analogue scale with a scale of $0-100$ $(0=$ no complaints, $100=$ very severe complaints $)$ to rate the perceived severity of the work-related upper extremity disorder (Sokka 2005).

We measured quality of life in two ways. First, general quality of life was assessed with the Dutch version of the 36-item Short-Form Health Survey (SF-36). The SF-36 consists of eight subscales: physical role functioning, emotional role functioning, social functioning, bodily pain, mental health, vitality, physical functioning and general health perception (Ware and Sherbourne 1992; Aaronson et al. 1998). Scores range from 0 to 100 (higher scores indicate better functioning). Reference data were derived from Aaronson et al. (1998). Second, quality of life was measured through visual analogue scales to rate the general quality of life and the level of current health on a scale of $0-100(0=$ completely unsatisfactory, $100=$ completely satisfactory; Streiner and Norman 2003; De Boer et al. 2004).
Disease-specific functional impairment was assessed with the Dutch version of the Disabilities of the Arm, Shoulder and Hand (DASH) questionnaire (Hudak et al. 1996; Beaton et al. 2001). DASH scores range from 0 to 100 (higher scores indicate a higher degree of disability). We used as a reference the scores from the study by Jester et al. (2005), who collected DASH data from a working population in Germany, comprising workers from different industrial sectors and including manual as well as nonmanual workers who were outside clinical considerations.

We assessed sickness absence with a questionnaire according to Burdorf et al. (1996) as a percentage of the self-reported number of hours of sickness absence over the previous 2 weeks divided by the number of working hours laid down in the employment contract. Sickness absence was also assessed as the self-reported number of days the patient had been on sick leave, partly or completely, during the previous 3 months.

\section{Statistical analysis}

We compared the scores on the DASH and the seven subscales of the SF-36 of the patients at T0 with the reference data with a one-sample $t$ test.

We used a linear mixed model (LMM) to compare the scores on the perceived severity of the disorder, general quality of life, the subscales of the SF-36, current health, functional impairment (DASH) and sickness absence directly after notification with the scores after 3, 6 and 12 months. We analysed the course over time of these variables as the main effect, selected the most fitting variance-covariance structure with the aid of the Akaike's score and executed the post hoc analyses to compare the scores between the subsequent measuring moments.

Furthermore, we investigated whether age, sex, work interventions and level of education at baseline were
Fig. 1 Determinants related to the origin, course and consequences of occupational diseases

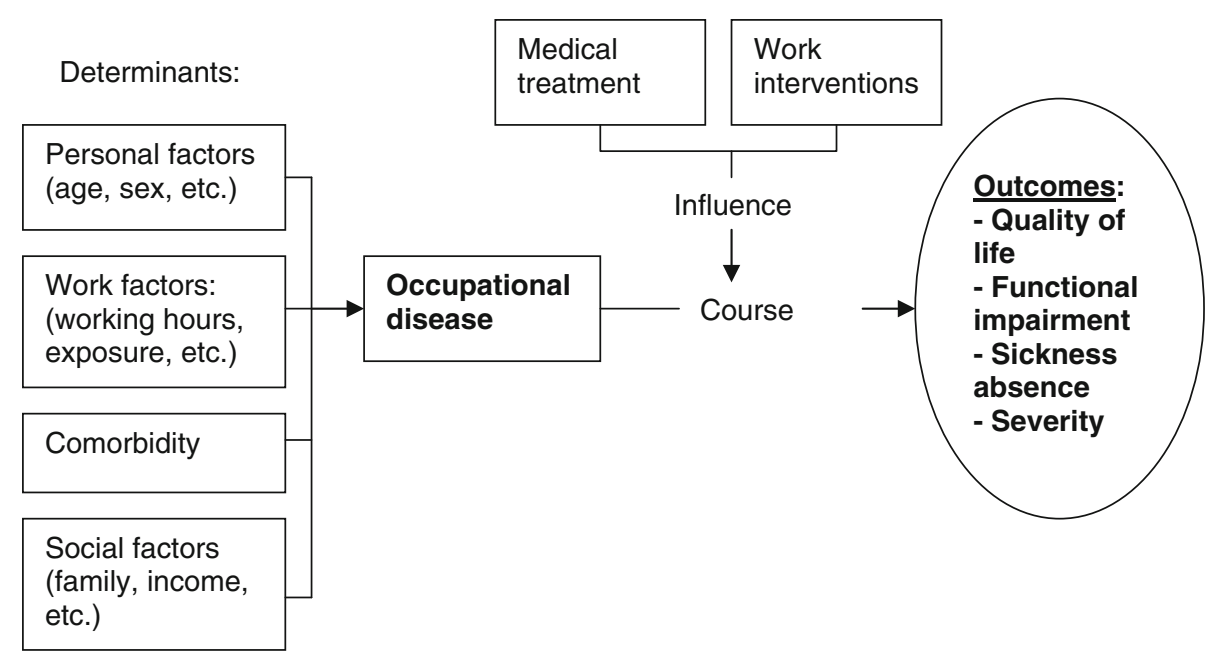


predictors of the course of the perceived severity of the disorder, general quality of life, the subscales of the SF-36, current health, functional impairment and sickness absence. Finally, we investigated whether the perceived severity of the disorder, general quality of life, the subscales of the SF-36, current health and functional impairment at baseline were predictors of sickness absence after 3, 6 and 12 months.

For the LMM analyses of the scores over time, $p$ values $<0.05$ were considered statistically significant, whereas for the post hoc tests, $p$ values $<0.01$ were considered statistically significant. Mean differences of 10 or more on a 100-point scale were considered clinically relevant in terms of effect size (Streiner and Norman 2003). All statistical analyses were conducted with SPSS 12.0.2.

\section{Results}

Forty-five occupational physicians participated in the sentinel surveillance project. We sent out T0 questionnaires to the 54 patients who were eligible to participate in the study. The response was 48 completed T0 questionnaires (89\%); two patients indicated that they no longer wanted to participate. At $\mathrm{T} 1$, we received 35 completed $\mathrm{T} 1$ questionnaires of the 52 we had sent out (response 67\%); seven patients indicated that they wanted to stop. We received 29 completed T2 questionnaires of the 45 we had sent out (response 64\%); four patients indicated that they wanted to stop. Finally, we received 24 completed T3 questionnaires of the 41 we had sent out (response $59 \%$, or $44 \%$ of the original 54 patients).

The characteristics of the participants at baseline are presented in Table 1 . The average age was 42 years, and $48 \%$ of the patients were women. Table 2 presents the baseline measurements (T0) of the perceived severity, the general quality of life as measured with a visual analogue

Table 1 Baseline measurements of participants with work-related upper extremity disorders $(N=48)$

\begin{tabular}{lcc}
\hline Variable & Number (\%) & Mean (SD) \\
\hline Age & & $42.4(10.2)$ \\
Sex & $23(48 \%)$ & \\
$\quad$ Women & & \\
Education level & $3(6 \%)$ & \\
$\quad$ Primary school & $15(31 \%)$ & \\
Lower vocational education & $17(35 \%)$ & \\
Intermediate vocational education & $4(8 \%)$ & \\
Higher vocational education/university & $9(19 \%)$ & \\
$\quad$ Other & & $33.7(7.8)$ \\
Working hours per week & & \\
\hline
\end{tabular}

scale and with the SF-36, the level of current health, the disease-specific functional impairment and the sickness absence. All of the subscale scores on the SF-36 and the DASH were statistically significant lower than the reference values of the general population.

Perceived severity of the disorder

Measurements over time showed that in $67 \%$ of the patients the perceived severity of the disorder declined more than 10 points (scale $0-100$ ) during 1 year of followup after notification. The average perceived severity of the disease declined statistically significant during the followup period from 68 at $\mathrm{T} 0$ to 40 at 1-year follow-up $(p<0.001)$. Post hoc analyses showed that the greatest decline in perceived severity of the disorder occurred in the first 3 months $(p<0.001)$ (Fig. 2).

\section{Quality of Life}

The average VAS score of the general quality of life did not change statistically significant during the follow-up period (T0: 84 , T3: 83; $p=0.150$ in the post hoc analysis). However, the average VAS quality of life scores with respect to health did increase statistically significant during the follow-up period from 57 at T0 to 69 at T3 $(p<0.001)$. Post hoc analyses showed that the greatest improvement occurred in the first 3 months, but the difference was not statistically significant $(p=0.033)$. The average scores on the SF-36 scales 'Bodily pain' $(p<0.001)$ and 'Physical role functioning' $(p<0.001)$ increased statistically significant during the follow-up period. Post hoc analysis showed that the greatest improvement occurred in the first 3 months, statistically significant for both 'Bodily pain' $(p=0.001)$ and 'Physical role functioning' $(p=0.001)$ (Fig. 2). Except for 'Mental health', all the other average scores on the SF-36 scales improved during the follow-up period, but not statistically significant.

Disability and sick leave

In line with these findings, functional impairment declined by more than 10 points (scale $0-100$ ) in $80 \%$ of the patients. The average DASH score (representing functional impairment) decreased statistically significant from 43 at T0 to 22 at T3 $(p<0.001)$. Post hoc analyses showed that the greatest decline in functional impairment occurred in the first 3 months $(p<0.001)$.

The average percentage of sickness absence over the previous 2 weeks decreased statistically significant from $32 \%$ at T0 to $5 \%$ at T3 $(p<0.001)$. Post hoc analyses showed that the percentage of sickness absence over the previous 2 weeks at T0 differed statistically significant 
Table 2 Baseline values of perceived severity, quality of life as measured with a visual analogue scale and the SF-36, the level of current health, the disease-specific functional Impairment (DASH) and sickness absence in the work-related upper extremity disorder patient population $(N=48)$

\begin{tabular}{|c|c|c|c|}
\hline Variable & $\begin{array}{l}\text { Mean }(\mathrm{SD} / 95 \% \mathrm{CI}) \\
\text { Patients }\end{array}$ & $\begin{array}{l}\text { Mean general } \\
\text { population }\end{array}$ & $p$ value \\
\hline Perceived severity (VAS 0-100) & 68 (SD: 24) & na & \\
\hline General quality of life (VAS 0-100) & 84 (SD: 14) & na & \\
\hline Current health (VAS 0-100) & 57 (SD: 23) & na & \\
\hline \multicolumn{4}{|l|}{ Quality of life (SF-36) } \\
\hline Physical functioning & $74.2(70.4-78.1)$ & 89 & $<0.001 *$ \\
\hline Physical role functioning & $20.8(12.3-29.3)$ & 82 & $<0.001^{*}$ \\
\hline Bodily pain & $38.9(33.5-44.2)$ & 75 & $<0.001^{*}$ \\
\hline Social functioning & $73.2(66.4-80.0)$ & 84 & $0.003 *$ \\
\hline Mental health & $68.1(62.7-73.5)$ & 76 & $0.005^{*}$ \\
\hline Emotional role functioning & $68.8(57.1-80.5)$ & 86 & $0.005^{*}$ \\
\hline Vitality & $52.3(46.9-57.7)$ & 68 & $<0.001 *$ \\
\hline General health perceptions & $65.0(59.2-70.7)$ & 74 & $0.003^{*}$ \\
\hline Functional impairment (DASH) & $43.8(37.6-49.9)$ & 13 & $<0.001^{*}$ \\
\hline $\begin{array}{l}\text { Percentage of days absent due to sickness } \\
\text { in previous } 2 \text { weeks }\end{array}$ & 32 (SD: 38) & na & \\
\hline $\begin{array}{l}\text { Number of days absent due to sickness } \\
\text { in previous } 3 \text { months }\end{array}$ & 28 (SD: 29) & na & \\
\hline
\end{tabular}

The results of the SF-36 and DASH measurements were compared with the reference values in the general population (one sample $t$ test) na not available, * statistically significant

compared to $\mathrm{T} 3(p<0.001)$, but not compared to $\mathrm{T} 1$ $(p=0.027)$ and T2 $(p=0.099)$. The average number of days of sick leave during the previous 3 months decreased statistically significant from 28 at T0 to 6 at T3 $(p<0.001)$. Post hoc analyses showed that the percentage of sickness absence during the previous 3 months at T0 differed statistically significant compared to T3 $(p=0.004)$, but not compared to $\mathrm{T} 1(p=0.156)$ and $\mathrm{T} 2$ $(p=0.020)$ (Fig. 2).

\section{Predictors of improvement}

Only age turned out to be a statistically significant prognostic factor, indicating that patients above the age of 45 had worse scores on perceived severity of the disease $(p=0.002)$, functional impairment $(p=0.015)$ and the SF-36 subscale physical functioning $(p=0.001)$ than did younger patients in the course of the disease. In our study, sex, work interventions and level of education at baseline were not predictors of the perceived severity of the disorder, general quality of life, the subscales of the SF-36, current health, functional impairment and sickness absence after 3, 6 and 12 months. The perceived severity of the disorder, general quality of life, the subscales of the SF-36, current health and functional impairment measured at baseline were not predictors of sickness absence after 3,6 and 12 months.

\section{Discussion}

In a sample of cases of work-related upper extremity disorders registered as occupational diseases in the registry of the Netherlands Centre for Occupational Diseases (NCvB), perceived severity and functional impairment declined substantially during 1 year of follow-up after notification. Except for 'Mental health', all quality of life subscales improved during the follow-up period. The most pronounced improvement in perceived severity of the disease, functional impairment and quality of life was observed in the first 3 months after notification, whereas the decrease in sickness absence was slower. One year after notification, most values were close to the reference values in the general population, which suggests an almost complete recovery. Workers above the age of 45 had worse outcomes at the end of follow-up on perceived severity of the disease, functional impairment and quality of life than did younger employees. This study shows how a national registry can be used to gather information that is useful for prevention and management.

A strength of this study is that it covered a specific sample of work-related upper extremity disorders. Our respondents were employees whose occupational diseases had been diagnosed and reported by occupational physicians to the registry of the $\mathrm{NCvB}$. We conjecture that the sample represents the most severe cases in terms of 
Fig. 2 Comparison of the course of outcome variables in work-related upper extremity disorder $(n=48)$ during the follow-up period (directly after notification and after 3, 6 and 12 months) in relation to reference values from the general population. Fiiled diamonds value in patient population; filled squares reference value in general population
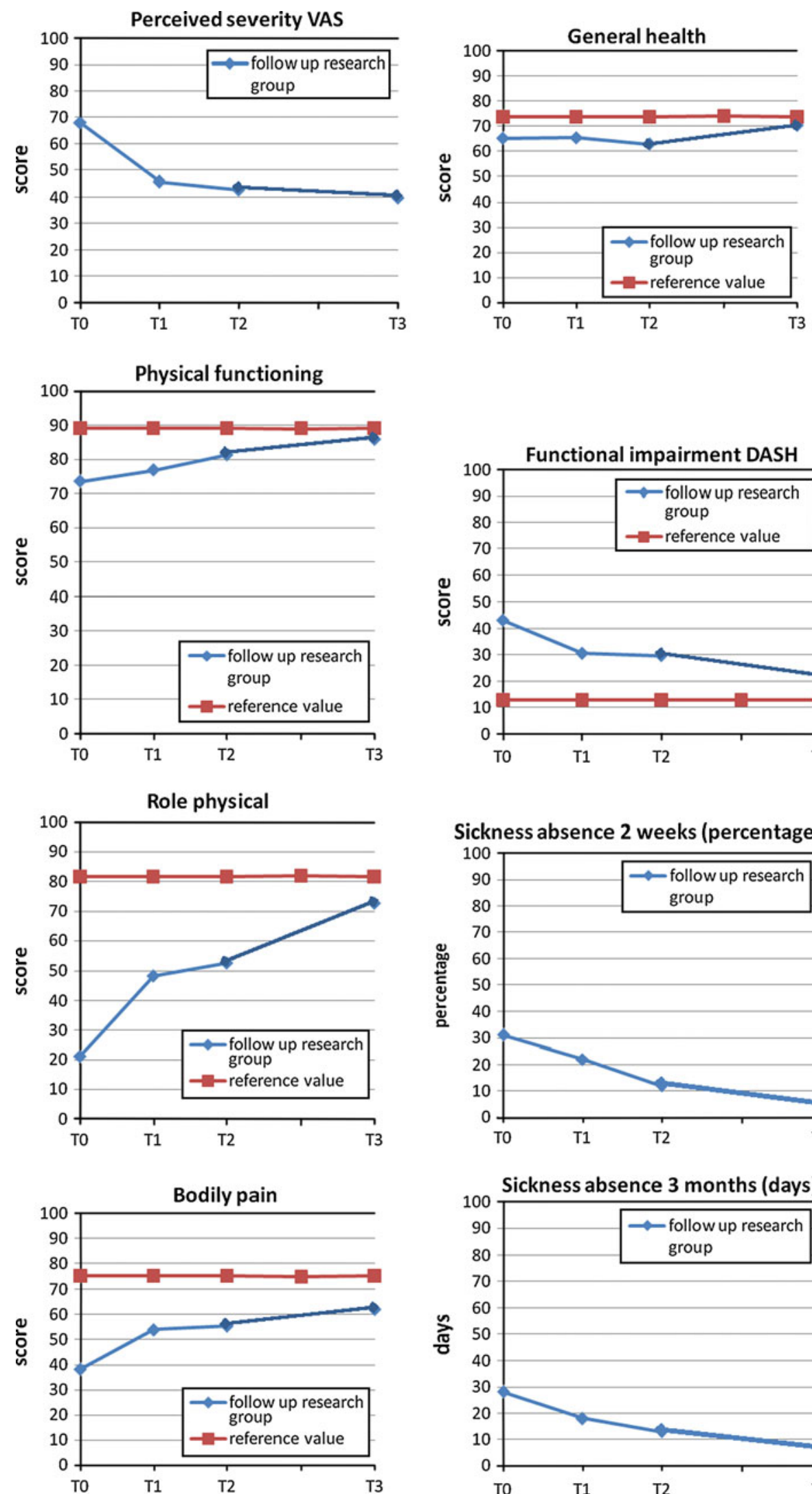
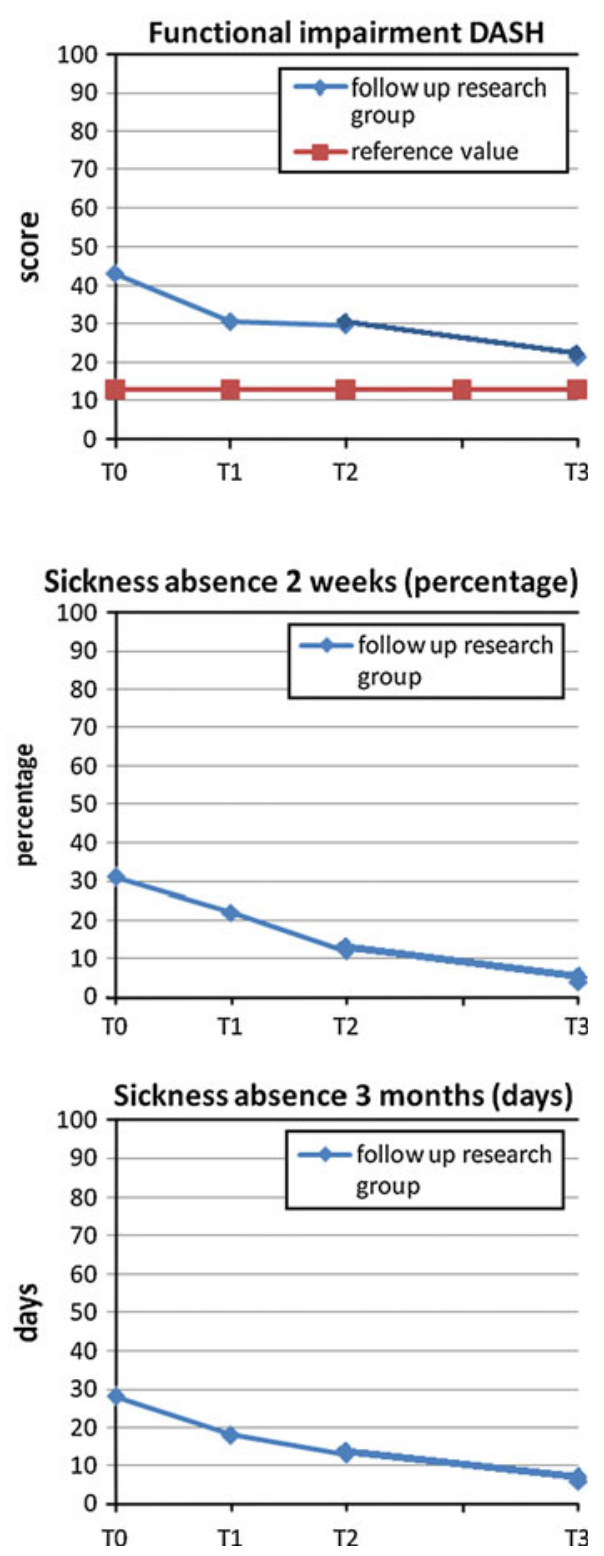
suffering, occupational disability and economic costs. A further strength of the study is that we could make use of the existing infrastructure of the Dutch national registry, which implies that the approach is efficient and that followup studies can be linked to other national registries.

At the same time, the focus on patients with severe complaints is a limitation of the study, as such might lead to an overestimation of severity, duration and consequences when interpreted for policy reasons without considering the selection of cases. A further limitation is that we analysed all cases of work-related upper extremity disorders, including various disorders with diverse clinical characteristics. The limited number of cases did not allow analysis on the level of the various diseases. The response rate at the end of the follow-up was quite low. A possible explanation is that the participants lost interest because their disorders were improving.

A limitation might be that we used self-report as a method to study sick leave instead of registered data. However, the concordance between retrospectively collected self-reported sick leave data and registered data showed high agreement on studies of for example Fredriksson et al. (1998) and Laestadius et al. (2008). Furthermore, it has to be noted that we used as reference the scores from a working population in Germany to study functional impairment. There might be differences between the Dutch and the German population with respect to this issue, but we do not have indications for that.

Aublet-Cuvelier et al. (2006) performed a follow-up study on the course of work-related upper extremity disorders during three consecutive years at a household appliance assembly company $(n=459)$. They found a relatively stable annual prevalence of $20-24 \%$ and a high annual incidence $(9.8-13.5 \%)$ of cases and of annual recoveries (37.0-44.3\%). The number of annual recoveries compares well with the favourable course in our study. Feleus et al. (2007) reported that $42 \%$ of a working population ( $n=473$ ) with non-traumatic complaints of the arm, neck and shoulder still reported complaints after 6 months. This compares to our finding that complaints had decreased in $33 \%$ of the patients after 6 months of followup. Cheng et al. (2002) found significant improvements in the SF-36 physical functioning and bodily pain scores after a physical therapy (PT) intervention, but noted a variation in outcomes across injury regions. Patients with elbow disorders needed more physiotherapy care and did not improve in the SF-36 physical role domain compared to shoulder and wrist/hand groups (Cole and Hudak 1996). We concluded that the results of several studies on the course of work-related upper extremity disorders seem to be generally comparable to our findings.

An interesting finding in our study was that the average VAS score of the general quality of life did not change, but the VAS quality of life scores with respect to health did increase. This might indicate that the functionality of the upper extremity does not have a major contribution to general quality of life.

Reitsma (1999) considered the possibility of follow-up studies linked to registries. He concluded that in most registries follow-up or historical information is not recorded, is short term or is missing and that the role of registries can be extended by creating longitudinal data. This can be done either by record linkage of existing data or by sample projects. This type of information is important in order to set priorities for preventive policy and to monitor the effects of policy interventions. The impact of diseases in terms of severity and duration has to be taken into account in policy making. Furthermore, trends can be monitored not only on the incidence of diseases but also on their course and consequences. If appropriate data can be obtained, the monitoring of economic costs could be added to the set of monitoring instruments.

Further research can be performed on the use of registries and related sample projects for preventive policy. A great advantage of using registries as a study base is the flexibility and efficiency of related sample studies, whereas primary studies are often expensive and take more time. On the other hand, the reliability of registries can be lower than that of primary studies. In general, the success of registries depend on the willingness of participants over a long time, the initiative to report lies with the reporter and often registries of occupational diseases are not focussed on one category of diseases but they cover a wide range of diseases. We recommend that studies should compare data from registries with data from primary studies. It would also be interesting to compare the course of work-related diseases to non-workrelated diseases as well as the influence of work-related exposures for the prognosis of diseases. In general, we plea for quality improvement of registries in order to obtain more reliable incidence figures (Spreeuwers et al. 2008).

The findings of our study suggest that complaints and quality of life improve substantially in the first 3 months after notification. Attention to elderly workers is needed, as they recover more slowly. We recommend evaluation studies on interventions to influence the course and consequences and prognostic studies to identify subgroups with a poor prognosis.

Conflict of interest The authors declare that they have no conflict of interest.

Open Access This article is distributed under the terms of the Creative Commons Attribution Noncommercial License which permits any noncommercial use, distribution, and reproduction in any medium, provided the original author(s) and source are credited. 


\section{References}

Aaronson NK, Muller M, Cohen PD, Essink-Bot ML, Fekkes M, Sanderman R, Sprangers MA, te Velde A, Verrips E (1998) Translation, validation, and norming of the Dutch language version of the SF-36 Health Survey in community and chronic disease populations. J Clin Epidemiol 51(11):1055-1068

Aublet-Cuvelier A, Aptel M, Weber H (2006) The dynamic course of musculoskeletal disorders in an assembly line factory. Int Arch Occup Environ Health 79(7):578-584

Beaton DE, Katz JN, Fossel AH, Wright JG, Tarasuk V, Bombardier C (2001) Measuring the whole or the parts? Validity, reliability, and responsiveness of the Disabilities of the Arm, Shoulder and Hand outcome measure in different regions of the upper extremity. J Hand Ther 14(2):128-146

Blatter BM (2001) De omvang van verzuim en arbeidsongeschiktheid door RSI (The size of sickness absence and disability due to repetitive strain injury). Elsevier, Doetinchem Bedrijfsinformatie (In Dutch)

Burdorf A, Post W, Bruggeling T (1996) Reliability of a questionnaire on sickness absence with specific attention to absence due to back pain and respiratory complaints. Occup Environ Med 53(1):58-62

Chen Y, Turner S, Hussey L, Agius R (2005) Physicians' beliefs in the assessment of work attribution when reporting musculoskeletal disorders. Occup Med 55(4):298-307

Cheng MS, Amick BC 3rd, Watkins MP, Rhea CD (2002) Employer, physical therapist, and employee outcomes in the management of work-related upper extremity disorders. J Occup Rehabil 12(4):257-267

CNAMTS (2007) Résultats 2004 des principeaux tableaux de maladies professionnelles. Database on the Internet. Available from: http:// www.risquesprofessionnels.ameli.fr/fr/maladies_professionnelles_ 2/ [Updated: 25/03/2009-Source: CNAMTS] (cited: 28-072010)

Cole DC, Hudak PL (1996) Prognosis of nonspecific work-related musculoskeletal disorders of the neck and upper extremity. Am J Ind Med 29(6):657-668

De Boer AG, van Lanschot JJ, Stalmeier PF, van Sandick JW, Hulscher JB, de Haes JC, Sprangers MA (2004) Is a single-item visual analogue scale as valid, reliable and responsive as multiitem scales in measuring quality of life? Qual Life Res 13(2):311-320

Ekberg K, Wildhagen I (1996) Long-term sickness absence due to musculoskeletal disorders: the necessary intervention of work conditions. Scand J Rehabil Med 28(1):39-47

European Foundation for the Improvement of Living and Working Conditions (2007) Fourth European Working Conditions Survey. Luxembourg: office for official publications of the European Communities; 2007. Information on the internet. Available from: http://www.eurofound.europa.eu/pubdocs/2006/98/en/2/ef0698en. pdf (cited: 28-07-2010)

Feleus A, Bierma-Zeinstra SM, Miedema HS, Verhagen AP, Nauta AP, Burdorf A, Verhaar JA, Koes BW (2007) Prognostic indicators for non-recovery of non-traumatic complaints at arm, neck and shoulder in general practice- 6 months follow-up. Rheumatology 46(1):169-176

Fredriksson K, Toomingas A, Torgén M, Thorbjörnsson CB, Kilbom A (1998) Validity and reliability of self-reported retrospectively collected data on sick leave related to musculoskeletal diseases. Scand J Work Environ Health 24(5):425-431
Hashemi L, Webster BS, Clancy EA, Courtney TK (1998) Length of disability and cost of work-related musculoskeletal disorders of the upper extremity. J Occup Environ Med 40(3):261-269

Health and Safety Executive (HSE) (2007) Self-reported work-related illness and workplace injuries in 2006/07: Headline results from the Labour Force Survey. Information on the Internet. Available from: http://www.hse.gov.uk/statistics/swi/index.htm. (cited: 28-07-2010)

Hudak PL, Amadio PC, Bombardier C (1996) Development of an upper extremity outcome measure: the DASH (disabilities of the arm, shoulder and hand) [corrected]. The Upper Extremity Collaborative Group (UECG). Am J Ind Med 29(6):602-608

Jester A, Harth A, Germann G (2005) Measuring levels of upperextremity disability in employed adults using the DASH Questionnaire. J Hand Surg 30(5):1074.e1-1074.e10

Karjalainen A, Niederlaender E (2004) Occupational Diseases in Europe in 2001. Statistics Focus 15(2004):1-8

Keogh JP, Nuwayhid I, Gordon JL, Gucer PW (2000) The impact of occupational injury on injured worker and family: outcomes of upper extremity cumulative trauma disorders in Maryland workers. Am J Ind Med 38(5):498-506

Laestadius JG, Ye J, Dimberg L (2008) Can we trust the answers? Reliability and validity of self-reported sick leave due to musculoskeletal symptoms. J Occup Environ Med 50(6): 611-613

Morse TF, Dillon C, Warren N, Levenstein C, Warren A (1998) The economic and social consequences of work-related musculoskeletal disorders: the Connecticut Upper-Extremity Surveillance Project (CUSP). Int J Occup Environ Health 4(4):209-216

Reitsma JB (1999) Registers in cardiovascular epidemiology. Enschede (The Netherlands): PrintPartners Ipskamp, pp 9-40

Riihimäki H, Kurppa K, Karjalainen A, Palo L, Jolanki R, Keskinen H, Mäkinen I, Saalo A, Kauppinen T (2004) Occupational diseases in Finland in 2002. Finnish Institute of Occupational Health, Helsinki

Sluiter JK, Rest KM, Frings-Dresen MH (2001) Criteria document for evaluating the work-relatedness of upper-extremity musculoskeletal disorders. Scand J Work Environ Health 27(Suppl 1): $1-102$

Sokka T (2005) Assessment of pain in rheumatic diseases. Clin Exp Rheumatol 23(5 Suppl 39):S77-S84

Spreeuwers D, Kuijer PP, Nieuwenhuijsen K, Bakker J, Pal T, Sorgdrager B, van der Laan G, Stinis HP, Brand T, Gryglicki J (2007) (2007) Signaleringsrapport Beroepsziekten 2007 (Alert Report on Occupational Diseases. Netherlands Center for Occupational Diseases, Amsterdam (in Dutch, with an English summary)

Spreeuwers D, de Boer AGEM, Verbeek JHAM, de Wilde NS, Braam I, Willemse Y, Pal TM, van Dijk FJH (2008) Sentinel surveillance of occupational diseases: a quality improvement project. Am J Ind Med 51(11):834-842

Streiner DL, Norman GR (2003) Health measurement scales, 3rd edn. Oxford University Press, Oxford, pp 33-34

Van Eerd D, Beaton D, Cole D, Lucas J, Hogg-Johnson S, Bombardier C (2003) Classification systems for upper-limb musculoskeletal disorders in workers: a review of the literature. J Clin Epidemiol 56(10):925-936

Ware JE Jr, Sherbourne CD (1992) The MOS 36-item short-form health survey (SF-36). I. Conceptual framework and item selection. Med Care 30(6):473-483 